\title{
Lidar measurements and Umkehr observations of the ozone vertical distribution at the Observatoire de Haute Provence
}

\author{
A-M. Lacoste, S. Godin and G. Megie \\ Service d'Aeronomie du CNRS, Universite Pierre et Marie Curie, \\ Paris, France
}

1.

Introduction

This paper compares results of lidar and Umkehr measurements, made during 1985-1991, which include 110 coincidences. The Umkehr ozone profiles were retrieved using the conventional Umkehr method (Gotz et al., 1934; Mateer and Dütsch, 1964), the short Umkehr method (De Luisi, 1979), and the recently developed new-conventional Umkehr method (Mateer and De Luisi, 1992) in which the conventional method is refered to as the "1964 algorithm" and the new-conventional method as the "1991 algorithm". Results obtained show good agreement between the ozone profiles derived using the new-conventional Umkehr method and lidar ozone profiles, emphasizing the influence of the temperature dependence of the ozone cross-sections on the Umkehr ozone retrievals.

\section{Lidar Measurenents}

Details of the experimental procedure have been given in previous publications (Pelon and Megie, 1982; Megie et al., 1985; Godin et al., 1989). In the present analysis, we include 290 lidar ozone profiles encompassing the time interval July 1985 to April 1991 for which, Umkehr data were available. These profiles correspond to the altitude range $15-45 \mathrm{~km}$ and thus to Umkehr layers 4 to 8 . The lidar data base also includes over 150 temperature profiles each for year, for 30 to $80 \mathrm{~km}$ altitudes (Hauchecorne et al., 1991). These profiles can be extended to lower altitudes using radiosonde data obtained daily at the nearby meteorological station of Nîmes, $120 \mathrm{~km}$ west of the Observatoire de HauteProvence.

\section{Umkehr Measurements}

Umkehr measurement data were analysed by $\mathrm{C}$. Mateer (private communication) using three differents methods. The conventional method uses the $C$ wavelength pair, the short Umkehr method uses three wavelengths pairs : $A, D$ and $C$, while the new-conventional Umkehr method recently introduced by Mateer and De Luisi (1992) also uses the $\mathrm{C}$ wavelength pair. The main differences between the two conventional methods are as follows: (1) the 1991 algorithm uses a-priori first guess ozone profile which depends on latitude and season and which takes into account the observed total ozone amount, as compared to only three a- priori profiles used in the 1964 algorithm; (2) the newconventional method uses Bass and Paur (1985) ozone absorption coefficients and their temperature dependence, taking into account a mean annual temperature profile for mid- latitude (Mateer, private communication, 1990), instead of constant temperature (229 K) Vigroux (1953) ozone absorption coefficients used in the conventional Umkehr method.

\section{Data Conversion}

Umkehr retrievals yield average values of the ozone partial pressure within the so-called "Umkehr layers" corresponding to fixed pressure intervals (Mateer et al., 1992). Lidar retrieved ozone values are generally expressed in ozone number density (molecules./cm 3 ) as a function of geometric altitude. In the altitude range between $15 \mathrm{~km}$ and $45 \mathrm{~km}$, where the comparable Umkehr and lidar data exist, the vertical resolution of the lidar measurements is better than the approximately $5 \mathrm{~km}$ thickness ( see the analysis of Rodgers in the Ozone Trends Panel Report WMO, 1990). For data comparison, we have averaged the lidar data over the Umkehr layers and the results have been expressed in number density. Coincidence between lidar measurements and Umkehr observations was considered obtained, if the measurements were performed during a 24 hours period of time. Lidar measurements are performed during nighttime and can thus be compared with either sunset umkehrs of the same day or sunrise umkehrs of the next day. Due to the lack of diurnal variation in ozone profiles below $40 \mathrm{~km}$ and to its low value, if present, between 40 and $45 \mathrm{~km}$ (Allen et al., 1984; Vaughan, 1984), no correction has been made for such diurnal effects.

\section{Comparison of Ozone Profiles Derived from Use of Three Umkehr Retrieval Methods}

In this comparison, ozone profiles obtained from the conventional Umkehr method were chosen as the reference. Biases among the various Umkehr methods were then evaluated using the following procedure. Denoting $X$ the ozone value obtained using the conventional method, and $Y$ the ozone value for either of the two other methods, data were averaged for the various Umkehr layers with indices $i$ over a total number of $\mathrm{N}$ observations with indices $\mathrm{j}$. The bias $\mathrm{Bi}$ in Umkehr layer $\mathrm{i}$, is then expressed as: 


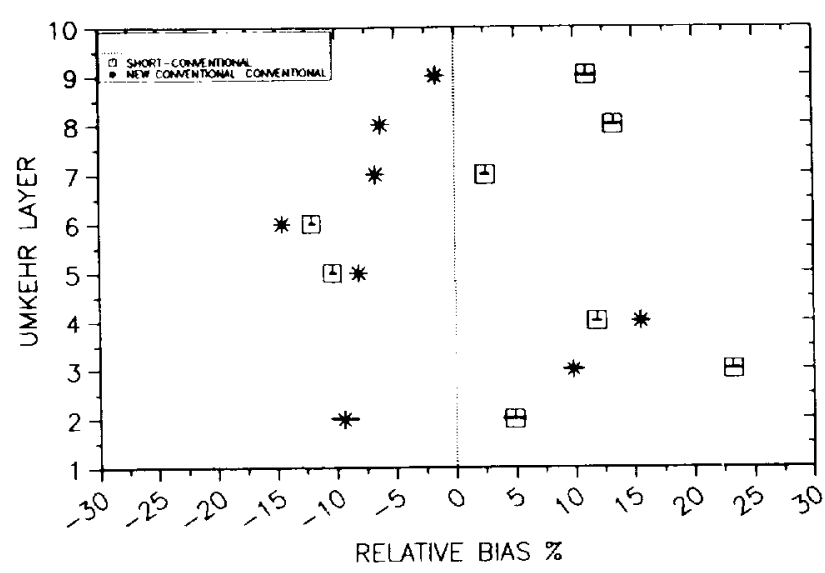

Figure 1: comparison between the Umkehr methods.

$$
\mathrm{B}_{\mathrm{i}}(\%)=\frac{1}{\mathrm{~N}} * \sum_{\mathrm{j}=1}^{\mathrm{N}} 100 \frac{\mathrm{Y}_{\mathrm{ij}} \mathrm{X}_{\mathrm{ij}}}{\mathrm{X}_{\mathrm{ij}}}
$$

The uncertainty limits, as given on the figures 1,2 and 3 of this paper, correspond to $\pm 2 \sigma$ intervals, where $\sigma$ is the standard deviation of the bias $\mathrm{Bi}$.

Considering figure 1 , the new-conventional and conventional Umkehr methods, show a positive bias in the lower layer 4 , and negative biases in layers 5 to 8 . The maximum negative bias is obtained in layer 6 , where it reaches $-12 \%$. The results obtained when comparing the conventional and the short Umkehr methods, lead to similar biases in layer 4 to 6 , whereas a larger positive bias is observed in layers 7 and 8 . The biases between the conventional and the new-conventional methods can be tentatively explained as follows. First, the use of the Bass and Paur coefficients introduces a negative change in the retrieved ozone profiles of $-3.5 \%$ over the whole altitude range (Mateer and De Luisi, 1992). Second, according to Rodgers (1990) and to the Ozone Trends Panel Report (WMO, 1990), taking into account the temperature dependence of the absorption coefficients introduces an additional distortion, because the short wavelength coefficient of the C-pair has a temperature sensitivity of $0.15 \% / \mathrm{K}$, while the long wavelength coefficient temperature sensitivity is $0.37 \% / \mathrm{K}$. Thus, atmospheric layers warmer than $229 \mathrm{~K}$, the average temperature of the Umkehr layer 6 , will have too much ozone in the retrieved conventional ozone profiles, and vice versa. Due to the inversion procedure itself, temperature differences in each of the Umkehr layers have a direct influence on the retrieved ozone values in all layers. A simple calculation can be made using the sensitivity of Umkehr retrieved ozone profiles to atmospheric temperature changes as given by the Ozone Trends Panel Report (figure 3.11 , WMO, 1990). This accounts for an additional negative bias of $4 \%$ in layers 8 and of $2 \%$ in layer 7 , while no bias is expected in layer 6 and only $1 \%$ positive biases in layers 4 and 5. Adding this effect to the direct effect of the absorption, however leaves unexplained biases of $+2 \%$ in layer $8,-0.5 \%$ in layer $7,-10 \%$ in layer $6,-3.5 \%$ in layer 5 and a positive bias of $10 \%$ in layer 4 . Such biases are observed in the altitude range of $20 \mathrm{~km}$ (layer 4 ) to $35 \mathrm{~km}$ (layer 7) where a maximum variability in the ozone field occurs on all temporal scales. The residual biases might thus be accounted for by the fact that the new-conventional Umkehr method takes into account more accurately this ozone variability, through use of a larger number of a-priori ozone profiles. To test such an assertion, the Umkehr methods need to be compared to an independent ozone measurement method, as performed in the next section.

\section{Lidar and Umkehr Ozone Profiles Compared}

Considerably more Umkehr observations (1969) have been made at the Observatoire de Haute Provence than have been used in the present analysis (290) because of the requirement for coincidences with lidar observations. The shorter Umkehr data base has, however, been tested for representative relative to the complete Umkehr data base and found to be adequate.
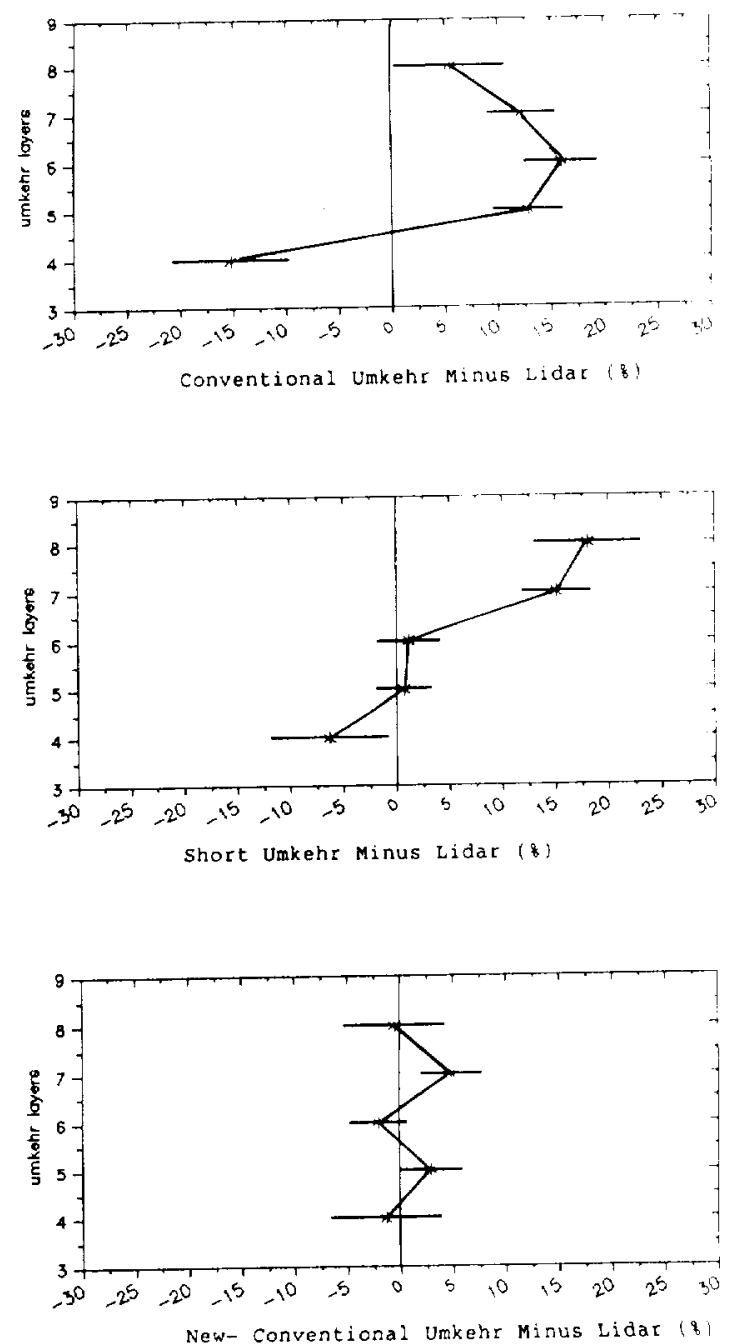

Figure 2: comparison between lidar and the three Umkehr methods. 
Umkehr and lidar ozone profiles are compared in figure 2, with biases computed as described in the previous section. Note that in Umkehr layer 4, all three Umkehr methods retrieve less ozone than do the lidar measurements, the maximum bias being observed for the conventional Umkehr method $(-15 \%)$. In Umkehr layers 5 to 8 , the conventional method yields larger ozone values than do the lidar measurements with biases reaching $15 \%$ in layer 6 to $5 \%$ in layer 8 . Biases related to the new-conventional method, however, are always less than $4 \%$. Considering the short Umkehr method, the biases are sligthly negative in layers 4 and 5 , and increase rapidly to reach more than $17 \%$ in layer $x$. It is clear from figure 2 that smallest biases occur in the case of the new- conventional Umkehr ozone retrievals, while the biases observed with the other two Umkehr methods reflect mostly the differences already analyzed in section 5 . In particular, the observed biases between lidar and new-conventional Umkehr retrieved ozone profiles do not appear to be statistically significant. This was confirmed by performing a statistical test, assuming that the differences between lidar and Umkehr ozone values were distributed according to the Student probability law, which applies to a small number of samples. This probability distribution was used to calculate the correlation coefficient for the $95 \%$ confidence interval. The results indicated that the Umkehr and lidar retrieved ozone values were in statistical accordance, within the uncertainty limits of the measurements.

Taking the above into account, a comparison was made between lidar measurements and new-conventional Umkehr retrieved ozone profiles on a monthly basis. In this analysis, the data were split according to the month of the measurement, with no distinction being made between the various years of observation. Results obtained should be considered only as indicative, due to the restricted data base presently available. The results, as presented on figure 3 , show that in almost all cases, the biases between lidar and Umkehr measurements are within the $2 \sigma$ confidence intervals. However, confidence intervals associated with some of the lidar data in Umkehr layers 4, 5 and 8 are large due to fewer lidar ozone values compared to the Umkehr ozone values, which induces a higher monthly variability of the lidar ozone concentration. In layers 6 and 7 the seasonnal variability has the same signature within error bars for both methods, with an unexplained difference in layer 6 during the month of June, where monthly lidar ozone value is higher than those obtained by the new-conventional method. In the layer 8 . variability of the lidar ozone concentration can also be partly accounted for by the signal-induced-noise effect on lidar measurements (Godin et al.,1989). This holds particularly true for lidar data obtained from 1985 to 1987 , corresponding to the first years of routine operation. Later, lidar observations were improved by incorporating into it, a mechanical chopper to block the intense signals backscattered from lower level altitudes.
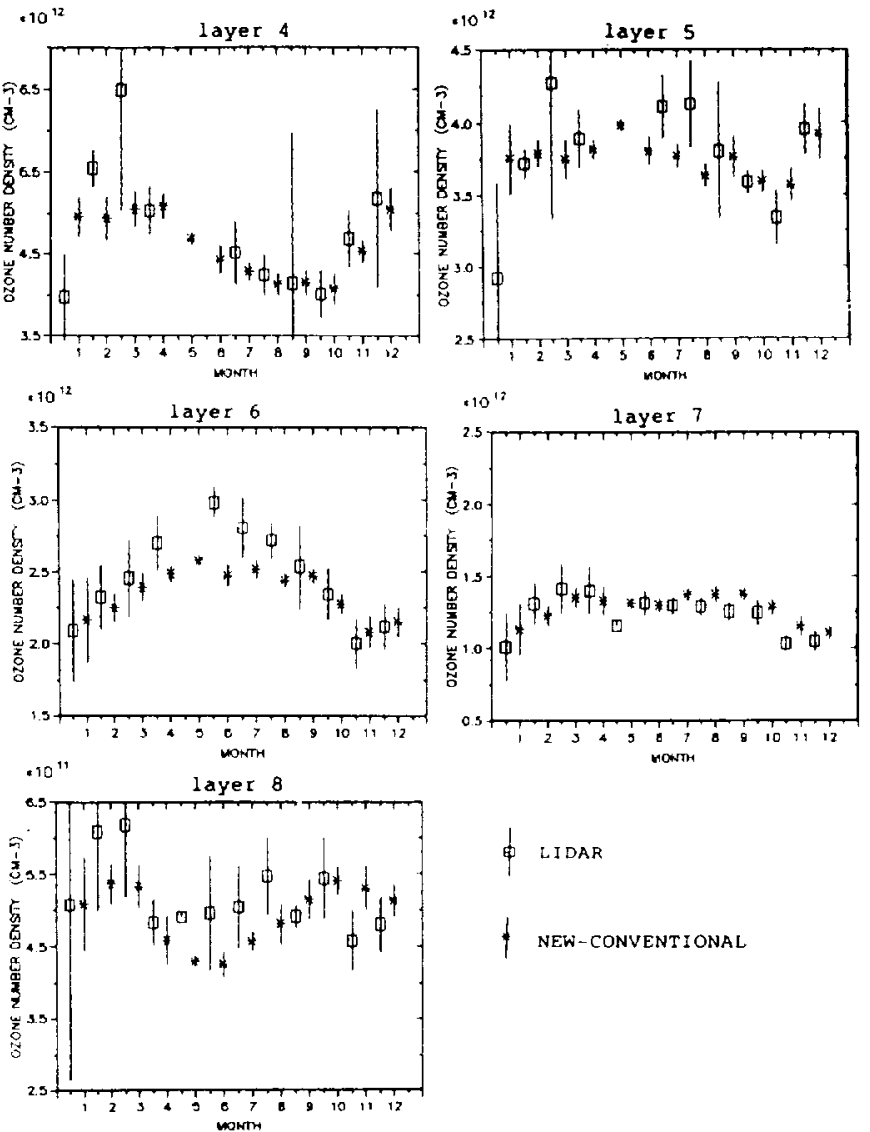

† NEW-CONVENTIONAL

Figure 3: ozone monthly mean annual variation for Umkehr layers 4 to 8 .

\section{Conclusion}

Operation at Observatoire de Haute Provence of a Dobson ozone spectrophotometer automated for Umkehr measurements (Komhyr et al, 1985) since 1983, has allowed comparison of these two ozone measurements techniques. Of 1700 Umkehr ozone profiles and 290 lidar ozone profiles obtained from 1983 to April 1991, the frequency of coincident observations was was as follows: 48 in Umkehr layer 4,55 in layer 5,95 in layer 6,100 in layer 7,81 in layer 8. A similar study (Lacoste et al., 1992), in a more restrictive available data base (1983 to 1988 ), already showed that biases, in results obtained when using the conventional, the short and the new- conventional Umkehr retrieval methods, can be explained largely in terms of differences taken into account by the different methods of the natural variability of the ozone distribution and the effect of temperature on the ozone absorption coefficients (Mateer and De Luisi,1991). Ozone values retrieved by the newconventional Umkehr method, are in good agreement with the lidar measurements with no statistically significant biases observed in layers 4 to 8 . Umkher layers 4 to 8 are the only Umkehr layers suitable for ozone trend analysis (Mateer et 
al., 1990; WMO, 1990). Ozone data obtained to date comprise unique background data for similar future research to be conducted at the Observatoire de Haute Provence, the first observatory site of the Network for Detection of Stratospheric Change.

\section{Acknowledgments}

We are indebted to Dr. C.L. Mateer for analysing the Dobson instrument observations and we would also like to thank the reviewers for their useful suggestions.

\section{References}

Allen M., Lunine J.I, and Yung Y.L, The vertical distribution of ozone in the mesosphere and lower thermosphere, J. Geophys. Res., 89, 4891- 4872, 1984.

Bass A. M. and Paur R. J, The ultra- violet cross- section of oozne: I. The measurements. In Atmospheric Ozone, C. S. Zerefos and A. Ghazi (eds). D. Reidel, Dordrecht, p. 606, 1985.

De Luisi J. J, Shortened version of the Umkehr method for obseving the vertical distribution of ozone. Appl.opt. 18, 18, 1979.

Godin, S., G. Megie, and J. Pelon, Systematic lidar measurements of the stratospheric ozone vertical distribution, Geophys. Res. Letters, 16, 6, 547-550, 1989.

Gotz, F.W.P., A.R. Meethan, and G.M.B. Dobson, The vertical distribution of ozone in the atmosphere, Proc. Roy. Soc. London, a145, 416-446, 1934.

Hauchecorne A., Chanin M. L. and Keckhut P. Climatology of the middle atmospheric temperature (30-90 KM) and trends as seen by Rayleigh lidar over southern france. J. geophys. 31, 1991.

Kohmyr W. D., Grass R. D., Evans R. D., Leonard R. K. and Semeniuk G. M., Umkehr observations with automated Dobson spectrophotometers. In Atmospheric Ozone, Procceedings of the Quadriennal Ozone Symposium, Halkidiki, Greece, September 1984. D. Reidel, Dordrecht, p. $316,1985$.

Lacoste, A.M., S.Godin and G.Megie, Lidar measurments and Umkehr observations of the ozone vertical distribution at the Observatoire de haute Provence, vol 54, n 5 , Journ. Atm. Terres. Phys., 1992.

Mateer, C.L. and Dütsch H. U., Uniform evaluation of Umkehr observations from the World Ozone Network, Part 1. Proposed standard evaluation technique, National Center for Atmospheric Research, Boulder, U.S.A, 1964.

Mateer, C.L., and J.J. De Luisi, A new Umkehr inversion algorithm, J. Atm. Terr. Phys., vol 54, n 5, Journ. Atm. Terres. Phys., 1992.

Megie, G., G. Ancellet, and J. Pelon, Lidar measurements of ozone vertical profiles, Appl. Opt., 24, 21, 3454-3463, 1985.

Pelon J. and Megie G. Ozone monitoring in the troposphere and lower stratosphere: evaluation and operation of a ground- based lidar station. J.geophys. Res.82, 4947, 1982.

Rodgers, C.D., Characterization and error analysis of profiles retrieved from remote sounding measurements, J. Geophys. Res., 95(D5), 5587-5595, 1990.
Vaughan, G., Mesosphenc ozone: theory and observation, Quart. J. R. met. Soc, 110, 239- 260, 1984.

Vigroux, E., Contribution a l'etude experimentale de l'absorption de l'ozone, Ann. Phys., 8, 709-762, 1953.

WMO, Report of the International Ozone Trends Panel: 1988, World Meteorological Organization, Global Ozone Research and Monitoring Project - Report no 18, World Meteorological Organization, Genenva, Switzerland, 199(). 